\title{
22. Connecting Science and Engagement: Setting groundwater extraction limits using a stakeholder- led decision-making process
}

\author{
Stuart Richardson, Ray Evans, Glenn Harrington
}

\section{Introduction}

Groundwater is a critical part of Australia's water resources. Though it is generally of lower available volume than surface water, it still provides key supplies for both consumptive and non-consumptive uses for key regions and at specific times. About 6000 gigalitres of groundwater is estimated to be extracted annually from aquifers across Australia, with this water used primarily for consumptive purposes, such as irrigation. Groundwater supplies about 15 per cent of water for irrigation across the Murray-Darling Basin (MDB), but this can increase to more than 70 per cent of the total water available in some catchments during extended dry periods.

At the national level, there are also high-value ecosystems that use groundwater, especially in dry periods when surface-water supplies are short. These ecosystems include terrestrial vegetation, aquatic systems in wetlands and rivers, and marine and sub-surface ecosystems.

Extraction of groundwater creates a change in the water resource, which in turn creates an impact on users or systems dependent on that resource. The question is not whether the impact will occur; rather it is a question of the location, magnitude and timing of impacts. There is a range of impacts from groundwater extraction that need to be managed, including

- depletion of storage (mining) within an aquifer

- increasing groundwater salinity

- reduced availability of groundwater to dependent ecosystems

- loss of production for consumptive users

- impacts to stream flow.

Governments and water-management agencies in Australia are in the process of (re)defining environmentally sustainable levels of groundwater extraction 
(as required by the National Water Initiative, NWI). In the past, the general approach has been to develop an extraction limit via a technical process and then provide that to the community via a water plan. In a sense, it was a 'DAD' (Decide, Announce and Defend) approach. Although there were successes with this approach, there were also occasions when it led to tensions. Generally, this tension came about through the over-allocation of groundwater resources because of a mind-set that focused on development in concert with the absence of information on what ecosystems occur in specific areas together with the environmental water requirements for these ecosystems.

This chapter outlines a different approach to the estimation of sustainable limits to extraction, where sound science is brought to stakeholders who are engaged in determining proposed extraction limits to inform policy development. The approach has been developed via a number of specific projects dealing with water-allocation planning in areas of significant use and where potential impacts to the groundwater resource can occur - that is, areas where adjustments in entitlements may be needed.

The unique aspects of the approach described in this chapter are

- re-conceptualisation of sustainable yield as acceptable yield

- characterisation of acceptable yield in terms of resource-condition limits

- use of a stakeholder-led process for making decisions.

\section{Policy Setting}

The approach — developed as an aid to groundwater management — was designed with the requirements of the NWI and the Natural Resources Management Act 2004 (SA) in mind. Specifically, the NWI requires that over-allocated and over-extracted systems are returned to environmentally sustainable levels of extraction (substantial progress by the end of 2010). The SA Natural Resource Management Act 2004 requires that

- the needs of the natural environment and human demands be considered in determining appropriate limits of extraction

- the rate of the use of water is sustainable, including to meet the reasonably foreseeable needs of future generations.

\section{What is Safe, Sustainable and Acceptable?}

The movement to sustainable development originated with the findings of the Brundtland Commission, Our Common Future, produced in 1987. This was a 
seminal step in the process of managing the impacts of humanity on the world's resources, and introduced the term 'sustainable development' into our lexicon. This process of sustainable development flowing from Brundtland led to the adoption of an ecologically sustainable development policy within Australia in the early 1990s.

In one sense, the concept of sustainability is a reaction to a perception that we are 'living beyond our means' in terms of the environmental cost of economic development. In the early years of considering this issue, it became apparent that certain groundwater systems were being used at a rate faster than they were being replenished. This led to the use of the term 'safe yield' to denote an upper limit to the total water available for use on an annual basis without depleting storage. Safe yield did not, however, promote the safeguarding of other, predominantly environmental, users of the resource. As can be seen, if all of the resource is used by one part of the user group then all other users will not be supplied.

Following on from this, there was pressure to limit use to lower rates, so that the needs of non-consumptive users could be balanced against broader expectations over resource use, generally for the environment. The standard approach has been to estimate the various components of the water balance and to then apportion a certain percentage of the long-term average recharge to consumptive uses. The percentage allocated usually approached 100 per cent of recharge; any reduction below 100 per cent depended on specific information on the presence of ecosystems. It was rare to find data that quantified the exact water requirements for ecosystem function. This approach generally worked well and addressed the issue of sustainability by limiting use to less than the long-term average recharge. The approach still did not preclude impacts from occurring, however, especially changes that affected key environmental assets. The approach also did not deliver optimum water-use outcomes in that the extraction limit defined was not spatially specific, and ecosystem function could still be impaired, even though the use was below the long-term recharge rate.

The historical approach made good ground in meeting sustainability objectives in a general sense; however, even though it was based on the knowledge of the water balance, it failed to take account of the concept that any extraction from a water source will create impacts somewhere in the hydrologic system.

The corollary to the knowledge that extraction will create an impact somewhere in the hydrologic system is that a decision is required when extracting water from such a system as to the acceptable level of impact that can be accommodated within the system. Obviously, a necessary condition for an acceptable impact is that the extraction cannot exceed the long-term average recharge rate. Apportioning a somewhat arbitrary percentage of the total-based generally 
on the need to manage current levels of consumption-is not, however, the best solution to the problem. A more rigorous approach is to define a set of limits that governs the agreed sustainability of the hydrologic system, and to manage extractions so that the impacts fall within the limits. This produces an acceptable level of impact according to specified resource condition limits. In one sense, the term sustainable yield should be replaced, at the management level at least, with the term acceptable yield.

In Australia, the NWI defines sustainable yield as the level of water extraction that, if exceeded, would compromise key environmental assets, or ecosystem functions, and the productive base of the resource. In addition, the National Groundwater Working Group has defined sustainable yield for groundwater as the groundwater extraction regime, measured over a specified planning time frame, that allows acceptable levels of stress and protects dependent economic, social and environmental values.

Each State and Territory implements this definition in a slightly different manner.

One can see from the National Groundwater Working Group definition of sustainable yield that the concept of acceptability of impact is already embedded and that the impacts are framed in terms of the values of the system. The definition does not prescribe that impacts should be avoided; rather, that they should be either optimised or minimised within a values framework.

\section{Using the Developed Water Balance}

In a large number of situations, the water balance considered as the basis for deriving the long-term average recharge rate (as part of normal operational sustainable yield analysis) is based on natural conditions - that is, conditions that existed prior to the development of the water source via extraction. The natural water balance does not, however, always provide the most useful information when considering the water balance of a groundwater source that is developed. This point was reported in the early 1980s by Bredehoeft et al. (1982) and later by Bredehoeft (2002) in what was called the 'water budget myth'. Essentially, the myth states that the natural recharge rate does not inform the sustainable yield that can come from an aquifer. Rather, when an aquifer is pumped, there is a capture of groundwater discharge as well as potential inducement of recharge to form a new water balance: the developed water balance. In this sense, the volumes of the various components of the developed water balance are what will determine the total available water pool from which the consumptive pool of water available for use is derived. A corollary of this consideration is that both the capturing of discharge and the inducement of recharge (generally from surface water) will have an impact somewhere else in the system. 
The myth was framed around groundwater considerations only, and it is interesting to consider it within the context of the total water balance. If we call the total volume of water available in a system - inclusive of both surface and groundwater - the available water pool then obviously conservation of mass says that this should remain the same (on average) in a closed system under different pressure states. If, however, the myth also says that the developed groundwater balance can change once pumping commences, logic says that the changed flows are compensated for either out of the surface-water balance or from outside the section of aquifer being considered.

\section{Case Examples}

The definition of groundwater sustainable yield clearly establishes an acceptability framework within the context of preserving the key values of the system being considered. If one can identify the values of the groundwater system - in terms of attributes such as its water quality, its reliability, the ecosystems that it sustains and its productive base - then an opportunity exists to set proposed limits on extraction such that the impacts on these values are at a level that is acceptable to all stakeholders. Such an approach has been attempted in three areas of South Australia (Figure 22.1).

\section{Northern Adelaide Plains Prescribed Wells Area}

The Northern Adelaide Plains Prescribed Wells Area (NAP PWA) is located on the northern outskirts of the Adelaide metropolitan area. Groundwater is used extensively for irrigation of vegetables, olives and grapes.

The majority of groundwater supplies is taken from the deeper, confined Tertiary aquifers. The upper $\mathrm{T} 1$ aquifer and underlying $\mathrm{T} 2$ aquifer are generally high yielding and contain low-salinity groundwater.

Historical groundwater use in the NAP PWA has resulted in seasonal groundwaterlevel declines forming cones of depression in the $\mathrm{T} 1$ aquifer to the south and a more permanent cone of depression in the T2 aquifer in the north. Winter extraction of groundwater, together with the usual high summer demand for irrigation water, maintains the cone of depression throughout the year.

The current (2000) water-allocation plan for the region provides for a maximum allocation of $26.5 \mathrm{GL} /$ year, which is greater than what is used. Groundwater use has varied between about $13 \mathrm{GL}$ and $19 \mathrm{GL} / \mathrm{yr}$ over the past 10 years. 


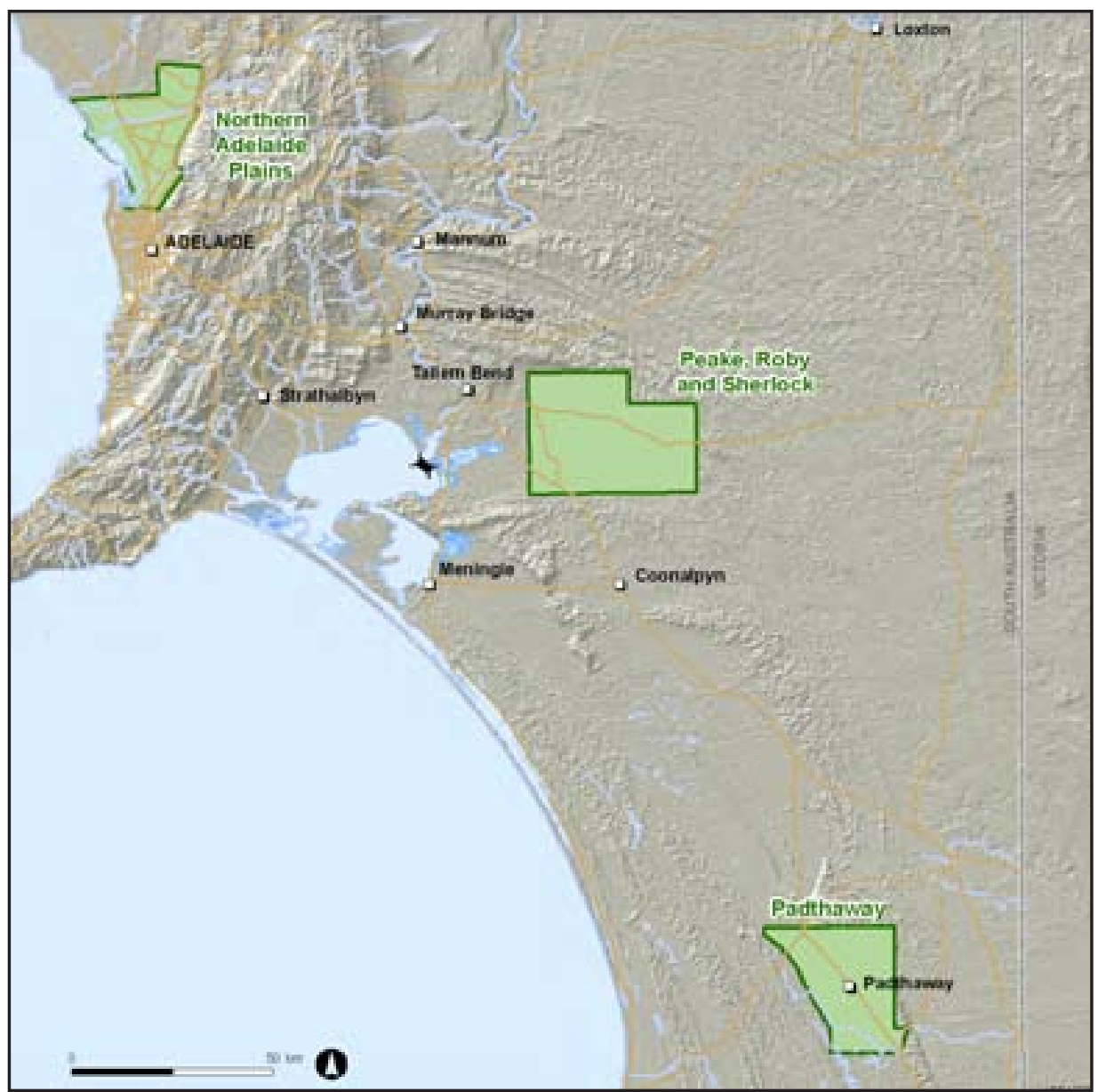

Figure 22.1 Location of the Peake, Roby and Sherlock Prescribed Wells Areas

This aquifer system has been characterised as potentially over-allocated but not necessarily overused. A new water-allocation plan is currently being prepared by the Adelaide and Mount Lofty Natural Resource Management (NRM) Board, which will set new extraction limits.

The Adelaide and Mount Lofty NRM Board has constructively engaged with stakeholders through a community-government committee and implemented the approach described in this chapter to derive a proposed extraction limit.

\section{Padthaway Prescribed Wells Area}

The Padthaway PWA is located in the south-eastern region of South Australia and covers an area of about $700 \mathrm{sq} \mathrm{km}$. Most groundwater is extracted from the shallow Padthaway Formation aquifer, which is less than $10 \mathrm{~m}$ below the ground surface. Groundwater is also extracted from the Bridgewater Formation beneath the adjacent hills. 
The volumetric allocation (following conversion from crop area to volumetric licences) was $89 \mathrm{GL} / \mathrm{yr}$, and use in 2005-06 was nearly $41 \mathrm{GL} / \mathrm{yr}$.

The State Government carried out a review of the condition of the groundwater resources in the area in early 2005. This review confirmed previous observations that although the Padthaway region has experienced minimal long-term change in groundwater levels, the rate of groundwater salinity increase is alarming (often 20-30 mg/L/yr), particularly for wine-grape growers (REM 2007). A great deal of investment in technical studies has shown the increasing salinity is a result of salt mobilisation following clearance of native vegetation over the adjacent hills and recycling of salty water via irrigation.

Analysis also suggested that four of the five groundwater-management sub-areas in the PWA will have licensed allocations exceeding the total available recharge to the aquifer following volumetric conversion. In response, the local NRM Board, which is charged with developing a water-allocation plan, proposed a default approach to address the perceived over-allocation. The proposed approach consisted of a series of five, equal-sized annual reductions in allocation to bring it below the total available recharge volumes, unless significant improvements in resource condition were observed after the third reduction. This approach would have meant that irrigators faced a significant reduction in their allocations in some areas. Whilst other sub-areas would require lesser reductions, many of the areas that are apparently over-allocated have not experienced long-term water-table decline.

The irrigators considered this default option unacceptable and developed an alternative strategy in response. The alternative strategy involved the quantification of proposed extraction limits using the approach described in this chapter.

\section{Peake, Roby and Sherlock Prescribed Wells Area}

The Peake, Roby and Sherlock PWA is located within the Mallee region of South Australia, approximately $140 \mathrm{~km}$ east of Adelaide. Groundwater is extracted from the unconfined Murray Group Limestone aquifer in the eastern part of the PWA and from the deep, confined aquifer within the Renmark Group under the coastal plain in the west. Groundwater is used for irrigation, stock, domestic and town-water supplies.

Metered groundwater extraction was 1.597 GL/yr in 2007-08.

A Water Allocation Plan (WAP) was recently completed, which sets allocation limits for this groundwater resource. The WAP was prepared in response to a decline in groundwater levels (of the order of 10-15 m) following development of irrigated areas. The decline in groundwater levels caused pumping infrastructure to become stranded in stock and domestic wells and increased the potential for lateral ingress of more saline groundwater from surrounding areas. 
The plan sets an allocation limit of $5.383 \mathrm{GL} / \mathrm{yr}$ across six management sub-areas. The allocation limits were set based on an analysis of draw down of groundwater levels and flow of saline groundwater from the west (SAMDBNRMB 2010a).

\section{Acceptable Yield and Resource Condition Limits}

Whilst the primary aim of managing any natural resource (including water) is to ensure the long-term sustainability of that resource (preferably in terms of both resource abundance and resource quality), defining short-term management objectives and/or targets can be less obvious. Ultimately, this task requires differentiation between what is 'sustainable' and what is 'acceptable'. The former has connotations that the resource will last forever, although recent definitions of sustainability for water-resource management purposes have tried to incorporate social and economic benefits as well as ensuring environmental longevity. When these three factors are considered simultaneously (providing a 'triple bottom line'), it might be more appropriate to use the term 'acceptable' rather than sustainable. It is therefore critical that all stakeholders are involved in the development of the adaptive-management approach.

Values of acceptable yield are determined through a process that links an understanding of how an aquifer system behaves when stressed with an analysis (via stakeholder engagement) of water-management objectives and resource condition limits.

Resource condition limits (RCLs) are upper limits to the levels of impact on groundwater resource condition that cannot be exceeded due to the extraction of groundwater. The RCLs are measured using resource condition indicators. In some groundwater-management areas, the RCL could relate to an indicator, such as the relationship between groundwater level and the saturated thickness of the aquifer (for example, Figure 22.2); it could be a specified groundwater level, it could be an indicator such as a rate of draw down of groundwater level over an annual cycle with a maximum rate specified as the limit, or it could be a groundwater quality indicator with the limit being the beneficial-use category.

In any case, the RCL is derived from a conceptualisation of how the aquifer system responds to stress, either based on historical time-series data (an evidenced-based approach) or from a numerical model (predictive analysis).

Resource condition limits are set through discussion with key stakeholders. Stakeholders in the groundwater resource-whether they are licensed irrigators, unlicensed stock or domestic users, dryland farmers, the regulators or representatives for the environment - will each have different views on what aspects of the resource are important to their industry and therefore which aspects should be protected. 


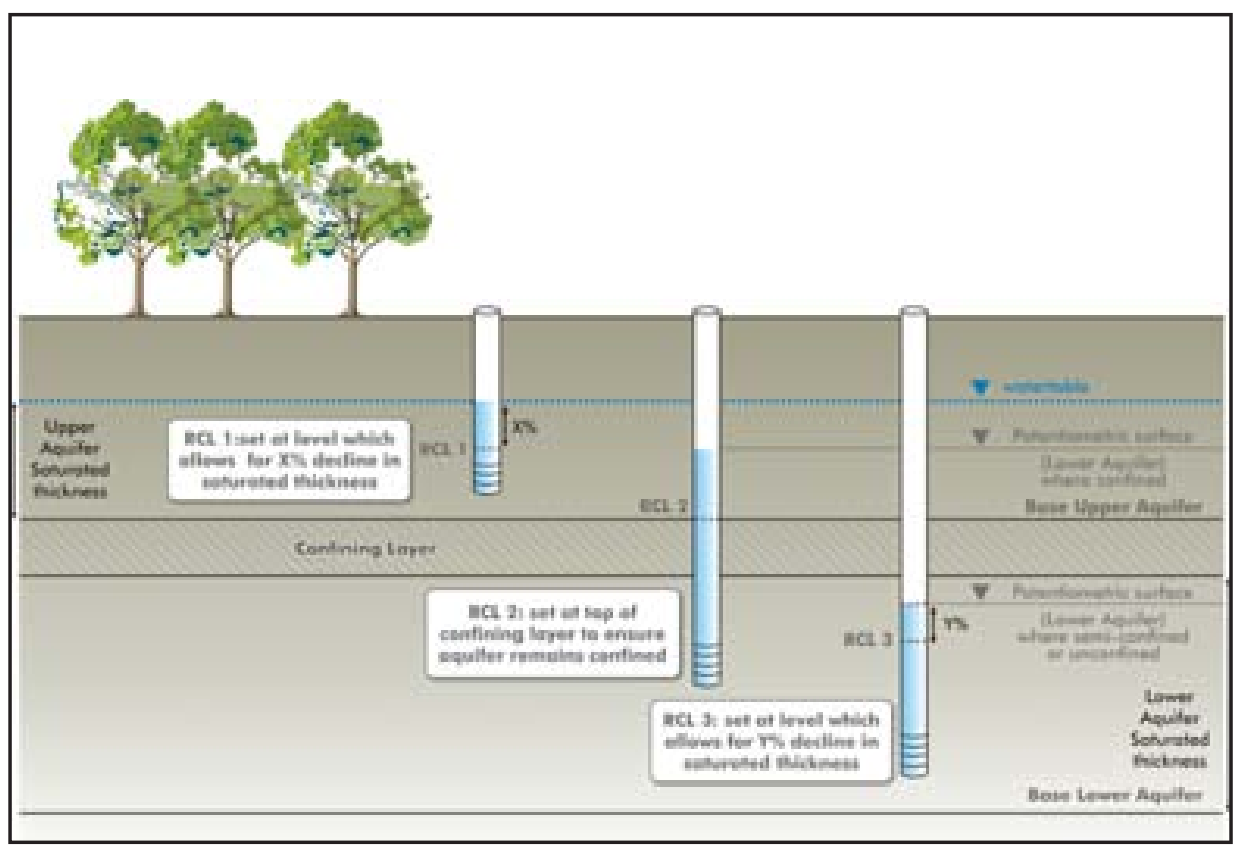

Figure 22.2 Examples of RCLs based on groundwater levels and confined aquifer pressure as percentage of aquifer thickness

\section{A Process to Determine Acceptable Groundwater Yield}

The process taken to determine the acceptable impacts is to identify the key values for the water source, the limits to the impacts such that the resource is protected to the desired level of all stakeholders, technical activities that translate the limits into an extraction volume, and a decision process that obtains agreement amongst stakeholders that a suitable solution has been reached. The process is shown schematically in Figure 22.3.

The flow of tasks shows that there is a mixture of both technical and general tasks that allows a decision-making process to proceed on the basis of informed discussion. It is critical that this technical linkage occurs, particularly in periods when the decision makers want to view the implications of various management scenarios. Equally, the technical support must be robust enough that scenario analysis has levels of certainty appropriate to the importance of the decision being made. 


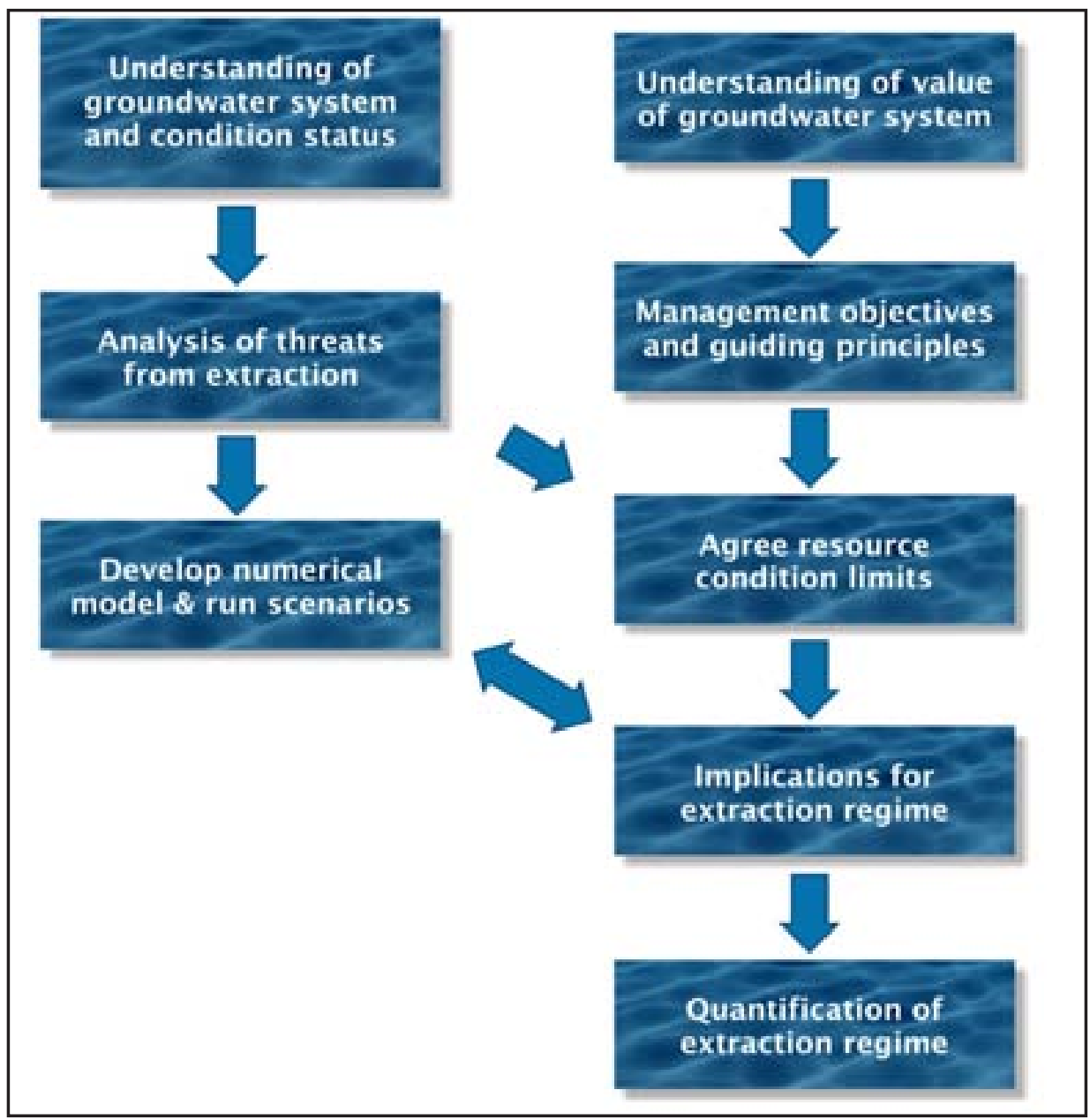

Figure 22.3 A flow of tasks that represents the technical process coupled with stakeholder engagement

\section{The Importance of Shared Objectives and Principles}

The strength of the process described here lies in the collaborative approach taken to decision making, and, specifically, to gaining agreement to groundwatermanagement objectives and principles between all stakeholders.

The engagement process provides the opportunity for all stakeholders to enter a debate that is backed by science and allows all interests to be heard. The objective of the discussions is to get all the viewpoints and issues disclosed, create a common understanding of the way the physical system operates, 
understand the limits to use and come to an agreement regarding an acceptable condition of the groundwater resource. The engagement process is supported by modelling analysis of a series of future scenarios.

It is important that all stakeholders are represented. It is implicit that if all stakeholders are well represented, and those stakeholders are able to represent their constituency in the decision process, there is consideration of the balance between environmental, social and economic issues. Where stakeholders do not have representative status from their constituency, some time is required to enable a combined stakeholder view to be input to the decision process.

In the case of the Northern Adelaide Plains and Padthaway, the stakeholder groups were comprehensive and included irrigator groups (with Padthaway involving different subgroups based on crop and type of irrigation system), regulators (with State representation of the NWI Agreement, policy, licensing and technical), planners, stock and domestic users, sleeper-licence holders (water entitlement-holders who do not use the water) and those representing the needs of the environment.

The conversations in the engagement process focus on perceptions of management issues, water-management objectives, values placed on the groundwater resource and principles that will guide decision making. In the case of Padthaway, the value of the resource was characterised as

- a high-security water resource (that is, high yield, good quality and reasonably low cost to access)

- having a capacity to generate high revenue per megalitre.

The agreed values were significantly weighted to socioeconomic outcomes. This was similar to the Northern Adelaide Plains, where the 'bankable' value of water entitlements was also recognised, as was the connection between the availability of water and the social value of the region.

A discussion of threats to values provides a mechanism for understanding the 'pressure points' on all stakeholder perspectives. In Padthaway, the key threats to values were related to the trends in the condition of the resource (for example, falling groundwater levels and rising salinity). This further emphasised the need to provide sound science and monitoring data in the discussion.

Our experience indicates that stakeholders are very capable of describing the management issues and highlighting the priority issues. This information provides the focus for technical investigations and further discussion around management responses. It is important that all issues are recognised and impacts quantified (that is, where, when and by how much?). 
Guiding principles provide the operating rules that govern the way groundwater resources can be managed. The common themes to these principles are

- equity

- equal share of benefits and costs

- sustainability (leave resource in no worse condition than the start)

- precautionary (will make a cautious decision if not enough data)

- manage for the long term across climate variability

- continuous improvement in knowledge base

- adaptive management

- security.

The discussion with stakeholders leads to the development of water-management objectives. These objectives reflect broadly what condition the groundwater resource should be in and what access users should have to the groundwater resource.

\section{Box 22.1}

The stakeholders in the Padthaway region developed the following objectives.

\section{Irrigators}

- $\quad$ seek to maintain groundwater levels (especially on flat) at least at 2004 levels (or some average)

- at break-in-slope seek to maintain groundwater salinity at acceptable levels $(800 \mathrm{mg} / \mathrm{L}$ or current)

- improve groundwater salinity on the flat

- flush stored salt from the soil

- create opportunities for recharge of water from surface-water sources.

\section{Regulator}

- $\quad$ needs to be NWI compliant

- share irrigators' objectives.

\section{Environment}

- $\quad$ maintain water levels under wetlands to west, although not sure of dependence of these wetlands on certain water levels

- level of salinity in water-too high for red gums at the moment, particularly on flats to the west.

\section{NRM Board}

- consider the social, environmental and economic impacts of WAP policy decisions

- continuation of a thriving viticultural and small seeds industry/enterprise in the Padthaway area in the next 100 years

- $\quad$ sustainability

- conditions of resource at least maintained if not improved

- $\quad$ no triggers are exceeded

- $\quad$ provide adequate water for the environment (for example, 10 per cent of recharge for environmental purposes-including through-flow)

- $\quad$ approach to groundwater management needs to be NWI compliant. 


\section{Resource Condition Limits}

The continuum of impacts due to resource use can be subdivided into three categories of acceptable, tolerable and intolerable, where intolerable impacts are those that must never occur, tolerable impacts are those that may occur but must be avoided by management action, and acceptable impacts are those that can be 'lived with' over a long time. Resource condition limits represent a 'sustainability position' or the boundary to an acceptable condition of groundwater. They define when an impact moves the resource to a tolerable or intolerable condition.

There are a number of key aspects to the agreement on RCLs to consider. Setting RCLs must be based on a sound understanding of the dynamics of the groundwater system and implications for threats to water-management objectives. For example, in the Padthaway region, the technical analysis indicated that the thickness of the productive zone of the aquifer was relatively small (about $5 \mathrm{~m}$ ) and excessive draw down of groundwater levels resulted in less water coming from the aquifer, affecting irrigators' capacity to obtain enough water for their crops.

It was necessary to support the stakeholder conversations related to this point with the time series of historical groundwater levels and connect that information with stakeholders' experiences. The time-series data had to be evaluated to understand the relationship between extraction and climate and geological variability. The issue of geological variability led to the conclusion that blanket approaches applied to the region as a whole were not appropriate and management targets needed to be spatially variable.

In other regions, RCLs were set to protect water access for stock and domestic users where declining groundwater levels were predicted to fall below the base of stock and domestic wells.

To be effective, measures of acceptable impacts and RCLs (and their related indicators) must

- be explicit in space and time

- relate to an agreed water-management objective

- be measurable.

Being explicit and measurable allows the RCLs to be operationalised. 
Examples of proposed RCLs from the Northern Adelaide Plains case are that the groundwater resource will be no worse off (and therefore the impacts will be acceptable) if

- the water level in the T1 aquifer is greater than the specified level in September each year as measured at agreed bores

- the water level in the T2 aquifer is greater than the specified level in September each year as measured at agreed bores

- $\quad$ the salinity in all aquifers does not exceed the beneficial use where it is below that level.

Our experience is that few RCLs can be constructed that relate to the protection of the environment. Environmental objectives are often provided but these broader statements cannot often be supported by the more detailed RCL. This occurs mainly because there is often a lack of monitoring infrastructure near ecological assets dependent on groundwater and because there is little quantified information regarding the groundwater needs of ecological assets. This obviously is a flaw and is being rectified.

\section{Determining Acceptable Yield}

The acceptable yield volume is generated through the evaluation of a series of extraction scenarios modelled using a groundwater-flow model. The groundwater-flow model estimates future groundwater levels (and in some cases salinity), making it an ideal tool to connect extraction scenarios with the agreed condition of groundwater (via RCLs).

In the case of Padthaway, the results from a series of model scenarios were compared with RCLs and it was noted that extraction at 48 GL/yr (about 45 per cent of allocation) maintained groundwater levels, through-flow and groundwater salinity within acceptable limits (Table 22.1).

Table 22.1 Summary of whether the model scenario results meet the $R C L$ requirement for the Padthaway PWA. The results suggest scenario 2 most clearly complies with the RCLs.

\begin{tabular}{c|c|c|c|c}
\hline RCL & $\begin{array}{c}\text { Scenario 01 } \\
\text { 100\%Allocations }\end{array}$ & $\begin{array}{c}\text { Scenario } \\
\text { 02 45\% } \\
\text { Allocations }\end{array}$ & $\begin{array}{c}\text { Scenario } \\
\text { 03 60\% } \\
\text { Allocations }\end{array}$ & $\begin{array}{c}\text { Scenario 04 } \\
\text { TARd }\end{array}$ \\
\hline June 2004 WL & $\mathrm{N}$ & $\mathrm{Y}$ & $\mathrm{Y} / \mathrm{N}$ & $\mathrm{Y}$ (mainly) \\
\hline $50 \%$ Saturation & $\mathrm{N}$ & $\mathrm{Y}$ & $\mathrm{Y} / \mathrm{N}$ & $\mathrm{Y}$ (mainly) \\
\hline Maintain N-S flow & $\mathrm{N}$ & $\mathrm{Y}$ & $\mathrm{Y}$ & $\mathrm{Y}$ \\
\hline
\end{tabular}


Similarly in the Northern Adelaide Plains, a proposed extraction limit was agreed that would meet the requirements of the proposed resource condition limit..

In the case of the Peake, Roby and Sherlock PWA, the proposed extraction limit was chosen based on maintaining groundwater salinity values within a suitable limit (salinity value of $5000 \mathrm{mg} / \mathrm{L}$ ) over the next 200 years (SAMDBNRMB, 2010b).

\section{Summary}

- The involvement of stakeholders in the decision-making process can be made to work and will generally lead to better outcomes. Meaningful engagement with stakeholders, and the sharing of key knowledge with them, allowed joint decisions to be made by regulators, irrigators and representatives of the environment. The maxim was 'start the discussion early and start with science and the basics'. The basics include the resource values, guiding principles and a shared view of resource-management objectives. The examples of Northern Adelaide Plains and Padthaway were successful partly because the stakeholders (irrigators) who were wearing the cost of changes to water entitlements also accrued the benefits.

- Couch extraction limits in terms of acceptable yield. Extraction will always have an impact. The question is: what impact is acceptable? If this is accepted then it is clear science does not provide all the answers and that value judgments are needed. A trade-off decision needs to be negotiated.

- Trade-off decisions need to be supported by reliable science and technical understanding. The decision process should be informed by the science, not deliberated entirely by technical specialists and revealed to stakeholders at the end of the process. A robust and reliable technical assessment requires comprehensive data as input.

- Ecosystems are not strongly represented in discussions. Our experience is that there is little quantitative science regarding ecosystem-water requirements brought to the discussion because of lack of data and limited understanding of the response of ecosystems to incremental changes in groundwater conditions. There are some exceptions to this where site-specific data are available.

- There is a need to develop tools that explicitly link changes to the condition of groundwater to indicators of social and economic value. These links were dealt with in a qualitative manner in the work described in this chapter, but quantitative analysis allows for a more rigorous evaluation of scenarios. 


\section{Basin Futures}

- The examples used in this chapter cover local to subregional scales. Further analysis is needed to understand whether the approach described can be used as a template for application at the broader basin scale.

\section{Acknowledgments}

This work is supported by examples from a series of case studies where the approach has been applied. The process has been applied in the Northern Adelaide Plains Prescribed Wells Area (NAP PWA), Peake, Roby and Sherlock Prescribed Wells Area (PRS PWA) and the Padthaway Prescribed Wells Area (PPWA).

The authors wish to thank the following organisations for support and funding to undertake these projects: Adelaide and Mount Lofty Ranges Natural Resource Management Board; South Australian Murray-Darling Basin Natural Resource Management Board; and Department for Water and South East Natural Resource Management Board.

The authors would also like to acknowledge RPS Aquaterra for the groundwaterflow and solute-transport modelling undertaken for Padthaway.

\section{References}

Bredehoeft, J. D. 2002, 'The water budget myth revisited: why hydrogeologists model', Groundwater, vol. 40, no. 4, pp. 340-5.

Bredehoeft, J. D., Papadopolus, S. S. and Cooper, H. H. jr 1982, 'The water budget myth', in Scientific Basis for Water Resource Management, Studies in Geophysics, National Academy Press, Washington, DC, pp. 51-7.

Resource \& Environmental Management Proprietary Limited (REM) 2007, Padthaway water allocation planning, Discussion Paper, Prepared for the Department for Water, Government of South Australia, Adelaide.

South Australian Murray-Darling Basin Natural Resource Management Board (SAMDBNRMB) 2010a, Water Allocation Plan for the Peake, Roby and Sherlock Prescribed Wells Area, South Australian Murray-Darling Basin Natural Resource Management Board, Murray Bridge, SA.

South Australian Murray-Darling Basin Natural Resource Management Board (SAMDBNRMB) 2010b, Guide to the Draft Water Allocation Plan for the Peake, Roby and Sherlock Prescribed Wells Area, South Australian MurrayDarling Basin Natural Resource Management Board, Murray Bridge, SA. 